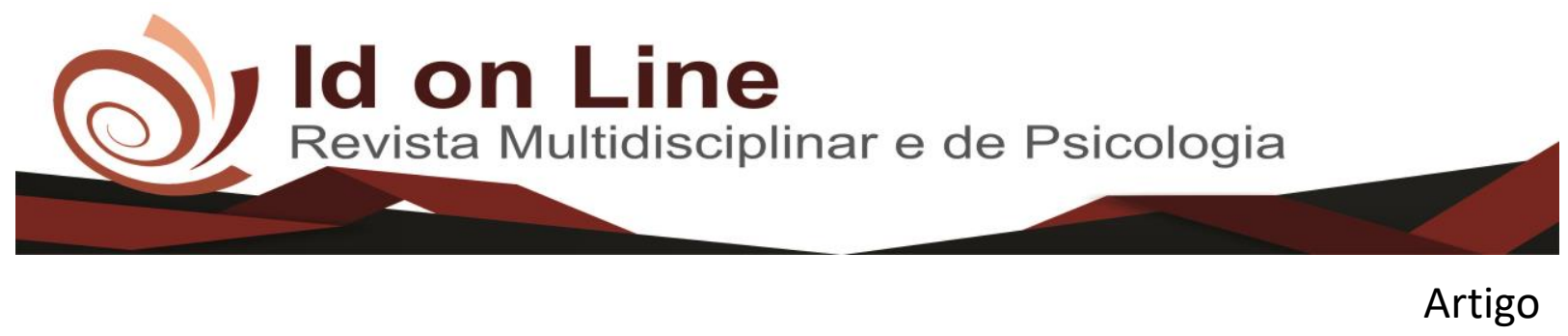

\title{
A Importância da Ética para o Profissional da Contabilidade
}

\author{
Francisca Sintia de Oliveira Sousa ${ }^{1}$; Ana Marília Barbosa Oliveira ${ }^{2}$
}

\begin{abstract}
Resumo: É possível observar que a contabilidade tem o intuito de ser o mais preciso possível nas suas tomadas de decisões, pois são informações importantes e que surtem efeitos de acordo com a maneira pela qual eles são produzidos. Relatórios contábeis, folha de pagamento, cálculos de impostos, são algumas das tarefas do qual o profissional contábil pode exercer. É ele também o responsável por fazer levantamentos de como anda a situação da empresa, apontando as situações que estão em conflito para que assim seja possível de ser sanados. Levando em consideração também que da falta de responsabilidade e planejamento pode gerar graves problemas afetando diretamente a organização. Diante disso se faz necessário um estudo mais aprofundado sobre a importância da ética para o profissional que confecciona essas informações, pois a ética está ligada diretamente ao conceito de honestidade, exigindo desse profissional comportamento adequado no exercício de suas atividades profissionais. $\mathrm{O}$ presente trabalho tem como objetivo mostrar a importância da ética para o profissional da contabilidade, apontando a necessidade de ter maiores cuidados ao trabalhar com informações. A metodologia aplicada a este artigo é de cunho bibliográfico, contendo uma amplitude de fundamentações teóricas de autores sobre a temática abordada. A pesquisa foi realizada entre os meses de fevereiro a novembro do ano de 2018 na cidade Várzea Alegre- CE.
\end{abstract}

Palavras chave: Contabilidade. Informações. Ética. Profissional Contábil.

\section{The Importance of Ethics for the Accounting Professional}

\begin{abstract}
It is possible to observe that accounting is intended to be as accurate as possible in its decision making because it is important information and that takes effect according to the way in which they are produced. Accounting reports, payroll, tax calculations are some of the tasks that the accounting professional can carry out. He is also responsible for making surveys of how the company's situation is, pointing out the situations that are in conflict so that it is possible to be healed. Taking into account also that lack of responsibility and planning can generate serious problems directly affecting the organization. In view of this, a more in-depth study on the importance of ethics is required for the professional who makes this information, since ethics is linked directly to the concept of honesty, requiring that professional behaves appropriately in the exercise of his professional activities. This paper aims to show the importance of ethics to the professional accounting, pointing out the need to take greater care when working with information. The methodology applied to this article is a bibliographical one, containing a range of theoretical foundations of authors on the subject. The survey was carried out between February and November of 2018 in the city of Várzea Alegre-CE.
\end{abstract}

Keywords: Accounting. Information. Ethic. Accounting Professional.

\footnotetext{
${ }^{1}$ Graduanda do Curso de Ciências Contábeis do Centro Universitário Doutor Leão Sampaio - UNILEÃO.

E-mail:sintiasousa06@gmail.com;

${ }^{2}$ Professora do Centro Universitário Doutor Leão Sampaio - UNILEÃO. Orientadora Prof ${ }^{a}$ Ms em Desenvolvimento Sustentavel pela UFCA. Docente do Curso de Ciencias Contábeis.

E-mail: marilia@leaosampaio.edu.br.
} 


\section{Introdução}

Diante das constantes mudanças no país no decorrer dos anos, tem-se a necessidade de se utilizar cada vez mais de informações úteis e seguras que sirvam de apoio a gestão e controle das organizações. Devido as perspectivas contemporâneas e a revolução tecnológica se percebeu que os profissionais das áreas estratégicas deveriam mudar o seu posicionamento e teriam que avaliar as condições e as incertezas que rodeiam a sociedade.

Ser um profissional da área contábil faz-se necessário que busque salientar as necessidades do mercado, atuando como um profissional com perspectivas de futuro. Diante disso, é necessário que esse profissional atue de maneira transparente no que diz respeito à prestação de contas do patrimônio das organizações.

Neste sentido, este trabalho tem como objetivo geral mostrar a importância da ética para o profissional da contabilidade, apontando a necessidade de ter maiores cuidados ao trabalhar com informações. A metodologia aplicada a este artigo é de cunho bibliográfico, contendo uma amplitude de fundamentações teóricas de autores sobre a temática abordada.

O presente trabalho tem como objetivos específicos trazer conceitos de contabilidade, ética, mostrar a importância de trabalhar com informações claras e precisas, sendo um estudo bibliográfico tendo seu referencial construído através de livros, sites e artigos sobre o tema.

Este trabalho se mostra relevante, no meio acadêmico, servindo como base para pesquisas futuras, importante para a sociedade, para empresários e futuros empresários e profissionais autônomos da contabilidade, pois mostrará a importância da ética nesse meio profissional.

\section{A Ciência Contábil}

Percebe-se que diante das constantes mudanças econômicas, mercadológicas e tecnológicas em âmbito mundial, nacional, regional e local, se torna necessário refletir sobre os aspectos situacionais das organizações, principalmente no que diz respeito ao profissional da área contábil (PADOVEZE, 2014).

A contabilidade no decorrer dos anos tem se tornado uma ferramenta indispensável para o desenvolvimento das mais variadas atividades não só no setor contábil. Ela tem participação fundamental para o fornecimento de informações que poderão significar a continuidade ou não das organizações (MARION, 2007). 
Acredita-se que o uso da contabilidade deixou de ser uma ferramenta restrita apenas aos profissionais da área contábil, onde está presente e tem auxiliando as pessoas que tenham interesse em obter informações sobre como anda a gestão de seus negócios (RIBEIRO, 2013). Entende-se que a contabilidade possui como objetivo controlar o patrimônio das empresas.Controle este que é feito através de coleta, armazenamento e processamento das informações advindas de fatos que por sua vez alteram tal massa patrimonial. Pode-se perceber que a contabilidade é um sistema de informação que controla o patrimônio de uma entidade, estando relacionado aos elementos que compõe o patrimônio (os bens) ou a moeda corrente do país (PADOVEZE, 2014).

\begin{abstract}
A contabilidade é o instrumento que fornece o máximo de informações úteis para uma tomada de decisões dentro e fora da empresa. Ela é muito antiga e sempre existiu para auxiliar a pessoa na tomada de decisões. Com o passar do tempo, o governo começa a utilizar-se dela para arrecadar impostos e a tornar obrigatório para a maioria das empresas (MARION, 2007. p. 28).
\end{abstract}

Nota-se que o uso da contabilidade está presente nos mais variados segmentos econômicos das organizações privadas, bem como nas entidades dos setores públicos, cujo objetivo é viabilizar e transmitir informações com mais segurança e agilidade, trazendo mudanças significativas para a gestão empresarial (SEBRAE, 2016).

Entende-se, nos tempos atuais, a contabilidade como uma técnica capaz de produzir, com
oportunidades e fidedignidade, relatórios que sirvam à administração no processo de
tomada de decisões e de controle de seus atos, demonstrando, por fim, os efeitos
produzidos por esses atos de gestão de patrimônio da entidade (KOHAMA, 2010, p. 25).

A contabilidade age de maneira eficaz e tem o intuito de ser o mais preciso possível, auxiliando as organizações nas suas tomadas de decisões, pois são informações importantes e que surtem efeitos de acordo com a maneira pela qual eles são produzidos. Trabalhos como relatórios contábeis, folha de pagamento, cálculo de impostos, são algumas das tarefas do qual o profissional contábil pode exercer (SANTOS; VEIGA, 2014).

Devido a crescente competitividade entre as empresas, elas estão sendo obrigadas a implantar melhorias contínuas nos seus processos de negócio para atrair mais clientes e melhorar os processos internos da organização. A obtenção de informações para fins gerenciais pode ser obtida de várias maneiras como, por exemplo: levantamentos, consultas diretas, consultorias, pesquisas acadêmicas, etc (ALMEIDA, 2010).

O objetivo da contabilidade é o controle patrimonial e esse controle é feito através de coleta, armazenamento e processamento das informações oriundas dos fatos que alteram essa massa patrimonial, uma entidade contábil é o conjunto patrimonial que pertence a uma pessoa física ou jurídica podendo ser ela sem fins lucrativos (PADOVEZE, 2014). 
Pode-se compreender que a contabilidade é um conjunto ordenado de conhecimentos que tem objetos e finalidades definidas, podendo ser considerada como uma habilidade técnica ou ciência, onde sua função é registrar, classificar, demonstrar, auditar e analisar todos os fenômenos que ocorrem no patrimônio das entidades, tendo como objetivo fornecer as mais diversas informações sobre possíveis variações de natureza econômica e financeira das organizações (RIBEIRO, 2013).

Acredita-se que a contabilidade também tem como principal ferramenta o patrimônio. Patrimônio é o conjunto de riquezas de propriedade de alguém ou de uma empresa uma entidade. São aqueles itens que a civilização convencionou a chamar de riquezas por serem raros, úteis, fungíveis e tangíveis e indispensáveis, sendo patrimônio um conjunto de bens (RIBEIRO, 2013).

Outra ferramenta é a chamada auditoria contábil que consiste no exame de documentos, livros e registros obedecendo a normas específicas de procedimento com o objetivo de verificar se as demonstrações contábeis representam adequadamente a posição econômico-financeira do patrimônio e os resultados do período administrativo (HOOG, 2013).

Muitas micros, pequenas e médias empresas no Brasil infelizmente apenas elaboram as demonstrações obrigatórias pela legislação a fim de atender somente as exigências fiscais. Este fato pode reduzir a competitividade das empresas nacionais ou dificultar que elas visualizem ou aproveitem a oportunidade ao não se apropriarem de informações relevantes que constam na contabilidade (SANTOS; VEIGA, 2014).

Diante o exposto é possível compreender que a contabilidade é utilizada como instrumento que facilita as organizações a atingir os seus objetivos, dando assim o suporte necessário para tal. Sendo esta, uma prestação de serviços com fornecimento de informações e avaliações da situação patrimonial das organizações.

Trabalhar com a contabilidade é estar sempre atento as mudanças constantes no mundo empresarial e principalmente ir se adequado a essas mudanças. Aquele profissional que não acompanhar essas transformações perderá o seu espaço e a credibilidade no mercado.

\section{O Profissional Contador}

O profissional contador deve ter capacidade para cumprir prazos, considerar as implicações de valores profissionais, ter atitude em situações de decisão, trabalhar com outros profissionais, ter responsabilidade social, ética profissional, ética legal inclusive em relação as leis, regulamentos e interesse público. É imprescindível que ele conheça de economia, governança corporativa, ambiente empresarial, comportamento organizacional, administração e decisões estratégicas, bem como capacidade de elaborar relatórios (SANTOS; VEIGA 2014). 
Uma ferramenta bastante usada pelos profissionais da contabilidade é o registro de todas as ocorrências patrimoniais por meio da escrituração, onde guardam todos os registros dos fatos da empresa, essa ferramenta é utilizada para que seja possível conhecer como anda a situação do patrimônio em um determinado momento da empresa para assim poder orientar de forma mais objetiva e clara a situação administrativa (HOOG, 2013).

O profissional da contabilidade deve manter-se sempre atualizado, dinâmico, comprometido e integrado com a empresa. Atualmente não é recomendada uma postura de contador que apenas receba as informações e registros contábeis, mas uma postura onde ele deve estudar alternativas que auxiliem na tomada de decisões no ambiente organizacional (SANTOS; VEIGA, 2014).

Para atingir a sua finalidade a contabilidade se utiliza de técnicas contábeis. Entre elas está a escrituração contábil onde é registrado os fatos que acontecem no patrimônio empresarial. Esse registro é feito de maneira cronológica e o que dá a contabilidade características verdadeiras da história do patrimônio empresarial. Outro meio que se utiliza na contabilidade é as demonstrações contábeis, tais como: inventários, balanços e outros (ALMEIDA, 2010).

O profissional da área contábil deve compreender as organizações bem como as relações e os trabalhos empresariais, possibilitando nas relações de trabalho as funções e atividades do negócio, conhecendo o ambiente organizacional. Deve ter conhecer áreas referentes à contabilidade, finanças, operacional, tributação negócio, do Direito Comercial, auditoria, controladoria e administração financeira (SANTOS; VEIGA, 2014).

A contabilidade também dispõe de uma técnica especializada conhecida como análise de balanços, esta permite decompor, comparar e interpretar essas demonstrações oferecendo aos interessados na riqueza patrimoniais dados analíticos e interpretação sobre os componentes do patrimônio e sobre os resultados da atividade econômica desenvolvida pela entidade, informações indispensáveis à tomada de decisão (PADOVEZE 2014).

$\mathrm{Na}$ atualidade a busca por informações referentes à contabilidade passou a ser de interesse dos mais diversos grupos de pessoas, onde estas estão cada vez mais preocupadas com que ocorre tanto no âmbito empresarial, quanto empregado ou empregador e na vida pessoal (SANTOS; VEIGA, 2014).

O controle dessas informações faz com que torne uma administração e gestão econômica e financeira melhor. Sem a contabilidade não seria possível conhecer o passado e o presente da vida econômica empresarial e não sendo possível elaborar planos eficazes de orientação administrativa para o futuro (ALMEIDA, 2010).

As informações devem ser compreensíveis para aqueles usuários possuem conhecimentos razoáveis dos negócios para que este tome conhecimento das informações contábeis e financeiras. 
Sendo fundamental que os demonstrativos sejam claros e que sempre que necessário contenham explicações para evidenciar fatos ou dados relativos ao patrimônio. Portanto divulgar as informações não pode ser apenas uma formalidade, mas também cumprir o seu papel de informar a sociedade e os interessados (SANTOS; VEIGA, 2014).

O profissional da contabilidade que se espera é aquele que contribua demaneira efetiva para o desenvolvimento da organização nas mais diversas áreas como, por exemplo, no recursos humanos, custos, encargos sociais e planejamento tributário (SANTOS; VEIGA, 2014).

Contudo é possível compreender que o profissional da contabilidade deve ter conhecimento nos diversos segmentos de mercado e organizacional bem como da organização sendo um setor importante para o desenvolvimento empresarial.

Com o intuito de manter seus clientes o profissional da contabilidade deve cumprir prazos, auxiliar na tomada de decisão, mostrar informações claras e precisas sobre a situação da empresa, bem como avaliando e prevenindo possíveis problemas que ponham em risco as organizações.

Diante disso observa-se que o profissional contábil além de ser um profissional atento as atualizações, também deve seguir o código de ética que regulamenta sua profissão.

\section{Campo de Atuação do Profissional Contador}

Pode-se perceber que o campo de atuação do profissional formado em ciências contábeis é atualmente bem amplo, onde acaba permitindo uma maior abrangência no que diz respeito à empregabilidade (ALMEIDA, 2010).

A contabilidade vem se desenvolvendo e ganhando novos seguimentos, deixando de ser somente a contabilidade tradicional mais conhecida como a contabilidade financeira, mas trazendo conceitos de contabilidade gerencial, estratégica, ampliando assim ainda mais o mercado de atuação desse profissional (SANTOS; VEIGA, 2014).

A contabilidade é uma importante ferramenta que auxilia a administração a tomar decisões, devido à coleta de informações e registros dos relatórios. Tomar decisões é uma tarefa importante principalmente no que diz respeito ao desenvolvimento empresarial com informações precisas e relevantes sobre o andamento da gestão financeira é possível que diminuam os riscos que uma empresa pode sofrer com decisões erradas (ALMEIDA, 2010).

Decisões de comprar ou alugar uma máquina, contrair uma dívida em longo prazo, reduzir custos, comprar, produzir mais, tudo está interligado a que tipo de decisão a empresa tem que tomar. A contabilidade é a linguagem dos negócios, onde é possível medir os resultados das empresas, avaliar o desempenho dos negócios dando diretrizes para tomada de decisões (MARION; MARION 2009). 
Diante dessa perspectiva observa-se que o campo de atuação do profissional da contabilidade vem ganhando espaço no mercado diante da acelerada evolução do ambiente econômico e tecnológico onde a contabilidade vai auxiliar de maneira significativa os administradores na gestão dos seus negócios.

\section{Funções do Contador}

A função básica do contador é de produzir informações úteis aos usuários da contabilidade para tomada de decisões. Porém, na sociedade em que vivemos alguns segmentos da economia acredita que a única função do contador é satisfazer as exigências do fisco de tal forma que está longe de ser a função mais importante do contador (MARION, 2007).

A contabilidade é uma ciência social, pois ela estuda o comportamento das riquezas que se integram no patrimônio em face das ações humanas. Por mais que a contabilidade se utiliza de meios quantitativos, não se pode confundir com ciências exatas ou Ciências Matemáticas que tem por objeto as quantidades consideradas abstratas que independem das ações humanas (MARION, 2007).

Já na contabilidade, as quantidades são simples medidas dos fatos que ocorrem em razão da ação do homem. A contabilidade surgiu basicamente da necessidade dos donos de patrimônio que desejavam mensurar, quantificar os ganhos das duas as empresas e controlar as suas riquezas (MARION, 2007).

Ao atuar na área da contabilidade este profissional deve fornecer informações sobre as demonstrações contábeis, devendo estas ser confiáveis e imprescindíveis para as empresas realizarem seu planejamento, acompanharem resultados, tomarem decisões, prestarem contas para a sociedade ou para captar recursos (SANTOS; VEIGA, 2014).

Diante disso, é preciso estar cada vez mais atentos ao se relacionar com as organizações, pois esses profissionais lidam constantemente com informações importantes e sigilosas, lidando diretamente com o funcionamento ou não de uma empresa. Ele atua diretamente no controle do fluxo e patrimônio empresarial (PADOVEZE, 2014).

Pode-se compreender com as colocações dos autores que a função do contador está ligada diretamente ao funcionamento da empresa desde a sua abertura até o seu fechamento. É ele quem acompanha e cuida das questões financeiras, tributarias e patrimonial da organização. Ele desenvolve guias, planilhas e demonstrativos dos resultados, bem como contas a pagar, a receber, impostos e auxilia os gestores nas tomadas de decisões. É uma profissão que vai exigir muita atenção e responsabilidade do profissional atuante. 


\section{Áreas de Atuação do Profissional Contábil}

A contabilidade é uma das áreas que oferecem mais oportunidades para o profissional e no atual cenário empresarial, é necessário ser um profissional atuante nos níveis operacionais, táticos e estratégicos das organizações.

Dentre as novas perspectivas profissionais na área contábil, podem ser citadas de forma resumida apresentada a seguir:

\section{Contabilidade Pública}

Acredita-se que contabilidade Pública tem seu surgimento desde as sociedades antigas onde o detentor do poder era somente aqueles com influencia no meio político consequentemente era o único que poderia dispor livremente de bens pertencentes a comunidade confundindo-se com os seus bens próprios. Era nítido o descontrole nos gastos públicos não existindo nenhum limite para tal ação, pois na época não existia um controle e supervisão dos orçamentos públicos (SILVA; NIYAMA, 2013).

Com o decorrer dos tempos normas foram sendo implantadas, normas estas de controle usadas inicialmente no Egito, Grécia e Roma, cujo objetivo principal era satisfazer as vontades do monarca para garantir a fidelidade dos administradores do que controlar as mudanças no patrimônio público (SILVA; NIYAMA, 2013).

Para Kohama (2010), a contabilidade publica é o ramo da contabilidade que estuda, orienta, controla e demonstra a organização e execução da fazenda pública o patrimônio e suas variações. Analisando registros e fazendo controle administrativo sobre determinado fato que acabam ocorrendo na administração pública.

A contabilidade pública é um dos ramos mais complexos da ciência contábil e tem por objetivo captar, registrar, acumular, resumir e interpretar os fenômenos que afetam as situações orçamentárias, financeiras e patrimoniais das entidades de direito público interno, ou seja, União, Estados, Distrito Federal e Municípios e respectivas autarquias, através de metodologia especialmente concebida para tal, que utiliza-se de contas escrituradas nos sistemas orçamentários, sistemas financeiros, patrimoniais entre outros. (KAHOMA, 2010)

É perceptível que estudar e investigar sobre o que ocorrido com o patrimônio publico é de extrema importância e necessidade, para que haja um controle dos gastos e investimentos nos empreendimentos necessários para o desenvolvimento publico, no entanto segundo Silva e Niyama (2013) somente nos últimos anos, tem ocorrido uma maior preocupação em utilizar-se da contabilidade para mensurar índices que possam refletir a qualidade da gestão. 


\section{Auditoria}

Entende-se auditoria como um recurso utilizado pelo sistema de controle interno para avaliar a eficiência e eficácia dos controles. Este servindo não só aos controles contábeis, como também aos controles administrativos. Desta forma este pode dar suporte a todos os setores da organização. Por sua vez, possibilita ainda uma visão sistêmica ao administrador, proporcionando um processo de decisão mais seguro e com menor incidência de irregularidades de atos administrativos durante sua gestão.

A auditoria das demonstrações contábeis visa as informações contidas nessas afirmações, assim é evidente que todos os itens, formas e métodos que as influenciam também estarão sendo examinadas (ATTIE, 2011).

Segundo Crepaldi (2004) a auditoria possui como objeto o conjunto de todos os elementos de controle do patrimônio administrado, os quais compreendem registros contábeis e outros diversos tipos de documentos que possam comprovar a legitimidade dos atos de administração, bem como sua sinceridade na defesa dos interesses patrimoniais. Ele defende que a auditoria pode ter também como objeto, fatos não registrados documentalmente, mas relatados por aqueles que exercem atividades relacionadas com o patrimônio administrado, cujas informações mereçam confiança desde que possam ser admitidas como confiáveis e seguras pela evidência.

\section{Contabilidade Gerencial}

A contabilidade gerencial é o processo de identificar, mensurar, relatar e analisar as informações sobre os eventos econômicos da organização, as informações são umas das principais fontes para tomadas de decisão e controle nas empresas. Uma dessas ferramentas é o chamado controle interno que é caracterizado como um processo que abrange diversos profissionais com a finalidade de diminuir os riscos e conflitos (ATKINSON et al, 2011).

Devido à crescente competitividade entre as empresas, elas estão sendo obrigadas a implantar melhorias contínuas nos seus processos de negócio para atrair mais clientes e melhorar os processos internos da organização.

Permanecer e sobreviver às mudanças inconstantes do mercado faz com que as empresas se adéquem cada vez mais a ferramentas que permitam que essas mudanças não aconteçam de forma descoordenada (MONTEIRO; BARBOSA, 2011). 
A contabilidade gerencial ou contabilidade de gestão é uma ferramenta indispensável para o sucesso de entidades independente de qualquer que seja o ramo de sua atividade. Avaliar as condições econômicas da empresa, como custos, rentabilidade de seus produtos, serviços, clientes e atividades, estão disponíveis no sistema de contabilidade gerencial (ATKINSON, 2011).

O processo globalizado provoca a necessidade de sobrevivência e permanência de um modelo de negócio em um ambiente de concorrência, gerando significativos desafios, obrigando os gestores das empresas a buscarem alternativas estratégicas, a fim de manter a empresa viva no mercado, satisfazendo seus clientes e atenta aos fatos da econômica (MONTEIRO; BARBOSA, 2011).

\section{Autônomo}

O contador como autônomo, pode desempenhar funções de auditor independente, consultor, empresário contábil, perito contábil e investigador de fraudes. Na Consultoria ele vai atuar como um agente de mudanças externas à empresa, o qual assume a responsabilidade de auxiliar os executivos e profissionais da referida empresa nas tomadas de decisões, não tendo, entretanto, o controle direto da situação (MARION, MARION, 2009).

\section{Ética Profissional}

\section{Conceito de Ética}

Para falar de ética é necessário entender o seu conceito, para alguns autores o conceito de ética se mostra subjetivo e intrínseco do ser humano. Fortes (2002), se refere a ética como sendo algo ligada à conduta do ser humano, onde esta pode ser visualizada do ponto de vista do bem e do mal.

A ética pode levantar questionamentos sobre os limites que rodeiam a vida do ser humano geralmente vindo da conduta humana, está intimamente ligado ao que diz respeito a conceitos de certo ou errado (LISBOA, 2010).

Entende-se que a ética é o estudo das avaliações do ser humano em relação às suas condutas ou às dos outros. Essas avaliações são feitas sob a ótica do bem e do mal, de acordo com um critério que geralmente é ditado pela moral (MOREIRA, 2012).

Ao se buscar o conceito de Ética Profissional, poderá chegar a uma série de normas que devem levar o indivíduo à aquisição de hábitos e à formação do caráter, incluindo os deveres e os 
direitos que cada profissional deve possuir para viver harmonicamente com os seus pares. Portanto, ser ético, significa ser um agente social cujas decisões são fundamentadas na moral do grupo ao qual pertence e são tomadas com base em valores e interesses que busquem o bem comum (LISBOA, 2010).

A ética está envolvida com os comportamentos do homem na sociedade, podendo também ser definida como conjuntos de normas de condutas que adveio de práticas reiteradas do ser humano.

\section{Ética do Profissional Contábil}

O profissional da contabilidade precisa apresentar diversas características entre elas está a perseverança, tenacidade e principalmente honestidade. A ética esta intimamente ligada ao conceito de honestidade. A ética para o profissional da contabilidade exige comportamentos adequados no exercício de suas atividades profissionais (MOREIRA, 2012).

O profissional da contabilidade lida constantemente com informações, sendo esta a sua principal ferramenta de trabalho. Diante disso na maioria das vezes esse profissional lida com informações sigilosas, garantir que essas informações estão sob o cuidado necessário e que sejam preservadas, é a obrigação desse profissional (LISBOA, 2010).

O Conselho Federal de Contabilidade aprovou um código de ética do profissional contador de acordo com a resolução CFC No 803/1996, vindo com o intuito de trazer atribuições e deveres no exercício das atividades desse profissional. Veio também com a finalidade de aprimorar os princípios do Código de Ética Profissional do Profissional da Contabilidade - CEPC.

Entre os deveres e proibições do contador, está de acordo com o artigo $2^{\circ}$ Resolução CFC

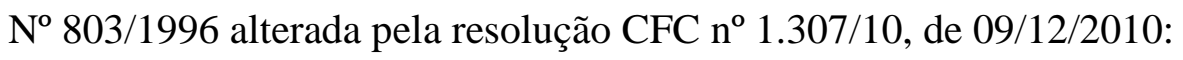

I - exercer a profissão com zelo, diligência, honestidade e capacidade técnica, observada toda a legislação vigente, em especial aos Princípios de Contabilidade e as Normas Brasileiras de Contabilidade, e resguardados os interesses de seus clientes e/ou empregadores, sem prejuízo da dignidade e independência profissionais;

II - guardar sigilo sobre o que souber em razão do exercício profissional lícito, inclusive no âmbito do serviço público, ressalvados os casos previstos em lei ou quando solicitado por autoridades competentes, entre estas os Conselhos Regionais de Contabilidade;

III - zelar pela sua competência exclusiva na orientação técnica dos serviços a seu cargo;

IV - comunicar, desde logo, ao cliente ou empregador, em documento reservado, eventual circunstância adversa que possa influir na decisão daquele que lhe formular consulta ou lhe confiar trabalho, estendendo-se a obrigação a sócios e executores; V

- inteirar-se de todas as circunstâncias, antes de emitir opinião sobre qualquer caso; VI renunciar às funções que exerce, logo que se positive falta de confiança por parte do cliente ou empregador, a quem deverá notificar com trinta dias de antecedência, zelando, contudo, para que os interesse dos mesmos não sejam prejudicados, evitando declarações públicas sobre os motivos da renúncia; [...] 
Pode-se compreender que o profissional contabilista é quem a pessoa, física ou jurídica, deve depositar muita confiança, não somente por ter acesso aos números da empresa, incluindo o seu faturamento, mas pela importância diferencial que tem a sua função como fator determinante do sucesso da empresa (VIEIRA, 2009).

Diante disso é possível afirmar que o profissional contábil tem grande importância e é considerado o fator determinante para o sucesso das organizações, contudo este profissional não pode transmitir insegurança, falta de credibilidade e desonestidade.

A Federação Internacional de contadores (IFAC) é uma organização global para a profissão contábil. Trabalha com a organizações de 130 países para proteger o interesse público, buscando alta qualidade dos contadores pelo mundo. Os sócios da IFAC representam 2,5 milhões de contadores empregados em funções públicas, na indústria, no comércio, no governo ou na academia. O IAESB (International Accouting Education Standards Board) elaborou um documento com objetivo de definir padrões internacionais para a educação na área contábil. Este documento entre outros aspectos apresentam, conteúdos, habilidades, valores profissionais, éticos, atitudes, capacidades profissionais e as competências relevantes para formação do contador (SANTOS; VEIGA, 2014.p.14).

A ética do profissional da contabilidade também se estende aos deveres do contador em relação aos colegas e á classe a que ele pertence. De acordo com o artigo $9^{\circ}$ Resolução CFC $n^{\circ}$ 1.307/10, de 09/12/2010 “A conduta do Profissional da Contabilidade com relação aos colegas deve ser pautada nos princípios de consideração, respeito, apreço e solidariedade, em consonância com os postulados de harmonia da classe."

Seguindo essa premissa é importante também salientar que para o exercício da profissão de contador, não basta apenas a preparação técnica, ele também deve aliar os princípios e valores morais e éticos aplicáveis a sua profissão, de modo a trazer informações transparentes e verdadeiras.

Contudo é preciso que o profissional da contabilidade exerça sua profissão com uma conduta ética. Seguindo as normas ditadas para o exercício da sua profissão, não sendo influenciado de maneira negativa pelas organizações, não devendo fraudar informações ou deixar de expor a real situação patrimonial da organização.

\section{Metodologia}

O referencial teórico foi construído através de pesquisas bibliográficas provenientes de artigos científicos, livros de autores renomados com o tema, como também foram realizadas pesquisas em sites relacionados à temática com o intuito de obter um melhor aprofundamento do assunto. Esta técnica explica o problema a partir de referências teóricas publicadas em 
documentos. Buscando conhecer e analisar as contribuições culturais ou científicas do passado existente sobre determinado tema ou problema. (LAKATOS; MARCONI, 2010)

Toda pesquisa implica o levantamento de dados de variadas fontes, quaisquer que sejam os métodos ou técnicas empregadas. Podendo ser feito um levantamento de dados no próprio local onde os fenômenos ocorrem ou ser elaboradas de acordo com documentos já existentes (LAKATOS; MARCONI, 2010).

Diante disso a presente metodologia buscou identificar através de livros, sites e artigos sobre a importância da ética para o profissional da contabilidade e como é a sua aplicabilidade.

\section{Considerações Finais}

Diante de tudo que foi exposto pode-se afirmar que a contabilidade com o passar dos anos vem sendo desenvolvida tornando-se uma ferramenta indispensável para a gestão da organização, principalmente em relação a sua aplicabilidade no controle do patrimônio empresarial.

Pode-se concluir também que o profissional da contabilidade, é responsável por fazer levantamentos de como anda a situação da empresa, apontando as situações conflitantes para que assim seja possível ser dirimidos. E que a falta responsabilidade e de planejamento pode gerar sérias consequências para aquelas empresas, gerando com maior facilidade os erros, fraudes, sanções e ate mesmo a falência dessas empresas.

Desta maneira, verificou-se que não é difícil entender que o profissional da contabilidade deve agir sempre levando em consideração os preceitos morais e éticos para que se possa verificar com maior exatidão e garantir que tudo ocorra da melhor maneira possível para assim poder obter os melhores resultados.

A pesquisa alcançou o objetivo esperado que foi fazer um levantamento bibliográfico sobre a importância da ética para o profissional da contabilidade, essa pesquisa servirá como base para pesquisas futuras, sendo de grande importância para o meio acadêmico, para a sociedade, para empresários e futuros empresários mostrando da importância da ética nesse meio profissional.

\section{Referências}

ATTIE, William. Auditoria: conceitos e aplicações. 6. ed. São Paulo: Atlas, 2011.

ATKINSON, Anthony A.; et al. Contabilidade Gerencial. Tradução: André Olímpio Mosselman Du Chenoy. $5^{\text {a }}$ edição. São Paulo: Atlas, 2011. 
ALMEIDA, Marcelo, Cavalcanti. Curso básico de contabilidade. 6.ed. São Paulo: Atlas, 2010

CREPALDI, Silvio Aparecido. Auditoria contábil: teoria e prática. 3 ed. São Paulo: Atlas, 2004.

FORTES. José Carlos. Ética e responsabilidade profissional do contabilista. Fortaleza: Fortes, 2002.

HOOG, Wilson Alberto Zappa. Contabilidade: teoria e fundamentos. 2.ed. Curitiba: Jaruá, 2013.

KOHAMA. H. Contabilidade pública: teoria e prática. São Paulo: Atlas, 2010.

LAKATOS, E \& Marconi, M. Fundamentos de metodologia científica. 10.ed.São Paulo: Atlas 2010.

LISBOA, Lázaro Plácido. Ética geral e profissional em contabilidade. 2 ed. São Paulo: Atlas S/A, 2010.

MARION, José Carlos. Contabilidade empresarial. 13. ed. São Paulo: Atlas, 2007.

MARION, José Carlos; MARION, Márcia Maria Costa. O ensino da contabilidade no Brasil. São Paulo: Atlas, 2009.

MOREIRA, Joaquim Manhães. A ética empresarial no Brasil. 5. ed. São Paulo: Pioneira Thomson Learning, 2012.

MONTEIRO, J. M.; BARBOSA, J. D. Controladoria empresarial: gestão econômica para as micro e pequenas empresas. Revista da Micro e Pequena Empresa, v. 5, n. 2, p. 38-59, 2011.

PADOVEZE, Clovis Luiz. Manual da contabilidade básica. 9 ed. São Paulo: Atlas, 2014.

RIBEIRO, Osni Moura. Contabilidade geral fácil. 9. ed. São Paulo: Saraiva: 2013.

RESOLUÇÃO Conselho Federal de Contabilidade - CFC - $\mathbf{N}^{\mathbf{0}} \mathbf{8 0 3 / 1 9 9 6 . ~ / 1 . 3 0 7 / 1 0}$, de 09/12/2010. Disponível em: http://www.portaldecontabilidade.com.br/nbc/res803.htm. Acesso em 20 abr.2018.

SANTOS, Fernando de Almeida; VEIGA, Windsor Espenser. Contabilidade: com ênfase em micro, pequenas e médias empresas. 3.ed. São Paulo: Atlas, 2014. 
SEBRAE - Serviço Brasileiro de Apoio à Micro e Pequena Empresa. Estudos e pesquisas. Disponível em: $<$ https://www.sebrae.com.br/Sebrae/Portal\%20Sebrae/Anexos /sobrevivenciadas- empresas-no brasil-relatorio-2016.pdf >. Acesso em: 15 abr. 2018.

SILVA, César Augusto Tibúrcio; NIYAMA,Jorge Katsumi. Teoria da Contabilidade. $3^{\text {a }}$ Ed. São Paulo: Atlas, 2013.

VIEIRA, Maria das Graças. Ética na profissão contábil. São Paulo: IOB Thomson, 2009.

\section{Como citar este artigo (Formato ABNT):}

SOUSA, Francisca Sintia de Oliveira; OLIVEIRA, Ana Marília Barbosa Oliveira. A Importância da Ética para o Profissional da Contabilidade. Id on Line Rev.Mult. Psic., 2019, vol.13, n.43, p. 295-309. ISSN: 1981-1179.

Recebido: 23/11/2018;

Aceito: $24 / 11 / 2018$ 